\title{
An uncommon clinical condition: chronic thrombosis of the inferior vena cava. A case report and review of literature
}

\author{
Una situazione clinica non comune: trombosi cronica \\ della vena cava. Un caso clinico e rassegna delle letteratura
}

\author{
Francesca Donati1, Leonardo Misuraca1, Chrysanthos Grigoratos², \\ Caterina Violo2, Stefano Vannucci3,Alberto Balbarini2
}

\begin{abstract}
An uncommon clinical condition: chronic thrombosis of the inferior vena cava. A case report and review of literature. F. Donati, L. Misuraca, C. Grigoratos, C. Violo, S. Vannucci, A. Balbarini.

The lifetime incidence of deep vein thrombosis (DVT) is approximately $0.1 \%$ in general population and even more uncommon in subjects below 40 years of age. Thrombosis of the inferior vena cava (IVC) is an exceptionally rare clinical condition, with etiological factors similar to lower limb DVT. We present a case of post-traumatic chronic obstruction of the IVC in 41 years-old man, caused by a prolonged squatted position, while he was working as a bricklayer. We visited the patient fifteen years after the onset of the first clinical setting showing a severe post thrombotic syndrome, as a consequence of the already diagnosticated thrombosis,
\end{abstract}

\begin{abstract}
involving predominantly the right inferior leg. Thrombophilia screening tests showed patient to be a heterozygous carrier of methylenetetrahydrofolate reductase (MTHFR) gene mutation. Computed tomography (CT) scan confirmed the thrombotic obstruction of the infrahepatic IVC, both common iliac veins, right external and internal iliac veins, with multiple collateral pathways. Because of thrombosis extension, inherited prothrombotic condition and the young age of the patient, we decided to continue life-long oral anticoagulant therapy.

Keywords: deep vein thrombosis, inferior vena cava thrombosis, inherited thrombophilia, oral anticoagulant therapy.
\end{abstract}

Monaldi Arch Chest Dis 2010; 74: 36-39.

\footnotetext{
1 Scuola di Specializzazione in Malattie dell'Apparato Cardiovascolare, Cardiothoracic and Vascular Department, University of Pisa, Pisa, Italy.

2 Angiology Division, Cardiothoracic and Vascular Department, Azienda Ospedaliero-Universitaria Pisana, University of Pisa, Pisa, Italy.

3 Radiology Department, Azienda Ospedaliero-Universitaria Pisana, University of Pisa, Pisa, Italy.
}

Corresponding author: Francesca Donati; Dipartimento Cardio-Toracico; Via Paradisa 2; I-56124; Pisa, Italy; Tel: +39 050/995392; Fax: +39 050/995397; Mobile phone: +39 347/0337975; E-mail address: francedonati@ hotmail.com;

\section{Introduction}

Deep vein thrombosis is a challenge for physicians of all disciplines. It usually complicates the course of a disease, but it might also be encountered in the absence of precipitating disorders. Thrombosis arises more often in the deep veins of the legs, although it can take place in any section of the venous system.

Genetic or acquired causes are frequently associated [1], which makes it difficult to decide which patients should be tested for hereditary thrombophilia and what diagnostic tests should be performed.

Thrombosis of the IVC has similar etiological factors to lower limb DVT [2]. Hypercoagulability (inherited or acquired thrombophilia), venous stasis secondary to extraluminal pressure (e.g. from tumours or inflammatory processes) and vessel injury (due to trauma) have all been implicated as primary mechanisms in the pathophysiology of DVT.

\section{Case report}

We present the case of a 41 year-old-man that 15 years ago was hospitalized for lower back pain (radiating to the inferior limbs and increased in severity during the preceding 72 hours), blushing, heaviness, edema and tumefaction of right inferior limb. Patient reported that these symptoms developed after a recent trauma, caused by a prolonged squatted position, due to his work as a bricklayer. He had no significant comorbidities and no family history of venous thromboembolism; however in the past he was an alcohol abuser. An abdominal and pelvic CT scan revealed a massive thrombosis of the infrarenal vena cava, with activation of collateral pathways between superior and inferior vena cava. At the thrombophilia screening tests, patient resulted carrier of a heterozygous mutation of the MTHFR gene, codifying for homocysteine. Therefore he was subsequently treated with intravenous heparin followed by oral anticoagulant therapy. 
In July 2009, patient was referred to our Department for a severe post thrombotic syndrome of the right leg. Ultrasound scan revealed the sequelae of DVT extending from common iliac veins bilaterally and involving right common femoral vein, right superficial femoral vein and right popliteal vein. We repeated an abdominal-pelvic CT scan that excluded congenital malformations of the IVC and confirmed the presence of a complete thrombotic obstruction involving the intrahepatic IVC, both common iliac veins, right external and internal iliac veins, with multiple collateral abdominopelvic (formed by subcutaneous anterior abdominal wall veins; lumbar, azygous, hemi-azygos and spermatic veins; hypogastric, peri-rectal, and peri-prostatic venous plexi. Portosystemic peri-esophageal, peri-gastric and peri-splenic collateral pathways) (see Figures 1-4).

Because of thrombosis extension, inherited prothrombotic condition and the young age of the patient, we decided to continue life-long oral anticoagulant therapy.

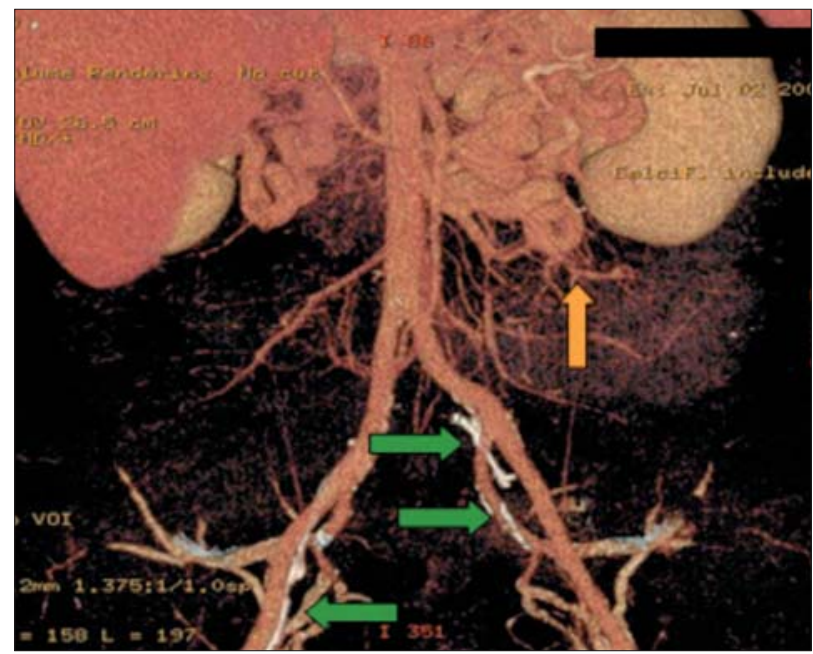

Figure 1. - 3D (Volume Rendering) reconstruction of CT scan showing extensive systemic-portal shunts (orange arrow). Green arrows indicate calcification of the iliac veins due to chronic thrombosis.

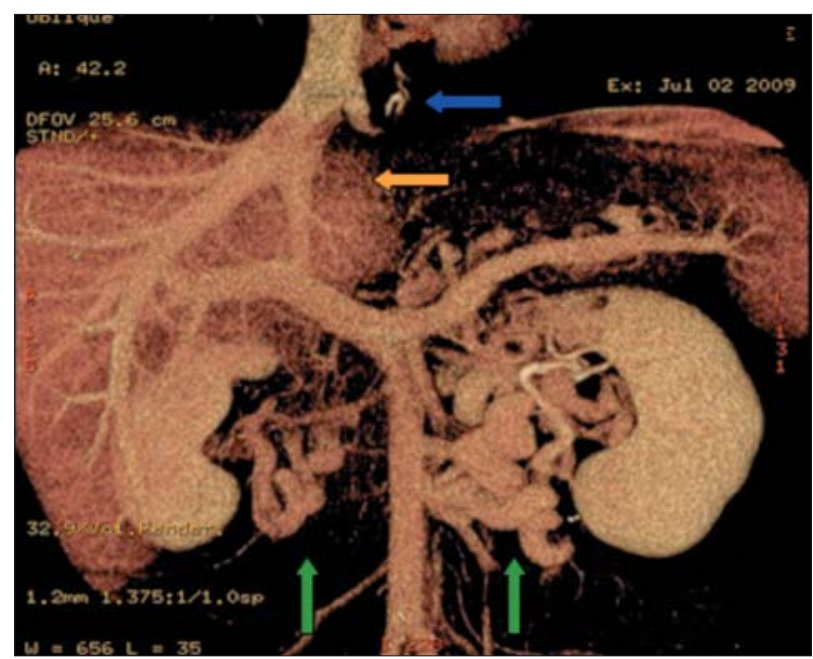

Figure 2. - Complete obstruction of the inferior vena cava (orange arrow). Green arrows indicate retroperitoneal ectasic collateral venous pathways. Enlarged perioesophaegeal plexi can also be seen (blue arrow).

\section{Discussion}

Pathogenesis of venous thrombosis involves three factors ("Virchow's triad"): venous stasis, vessel wall damage and hypercoagulability. The first factor (due to immobilization or venous obstruction) inhibits the dilution and clearance of activated coagulation factors; the second prevents endothelium from inhibiting coagulation and initiating local fibrinolysis; the third (inherited or acquired thrombophilia) promotes coagulation.

Thrombosis of the IVC has similar etiological factors to lower limb DVT [2]. Although the lifetime incidence of venous thrombosis is $0.1 \%$ (with this rate increasing from 0.01 percent among young adults to 1 percent among those who are at least 60 years old [3]), it still remains a rare condition, especially in subjects below 40 years of age.

Up to $50 \%$ of patients with an IVC thrombus presents bilateral lower extremities swelling and dilatation of superficial abdominal veins. Although some patients remain asymptomatic; nephrotic

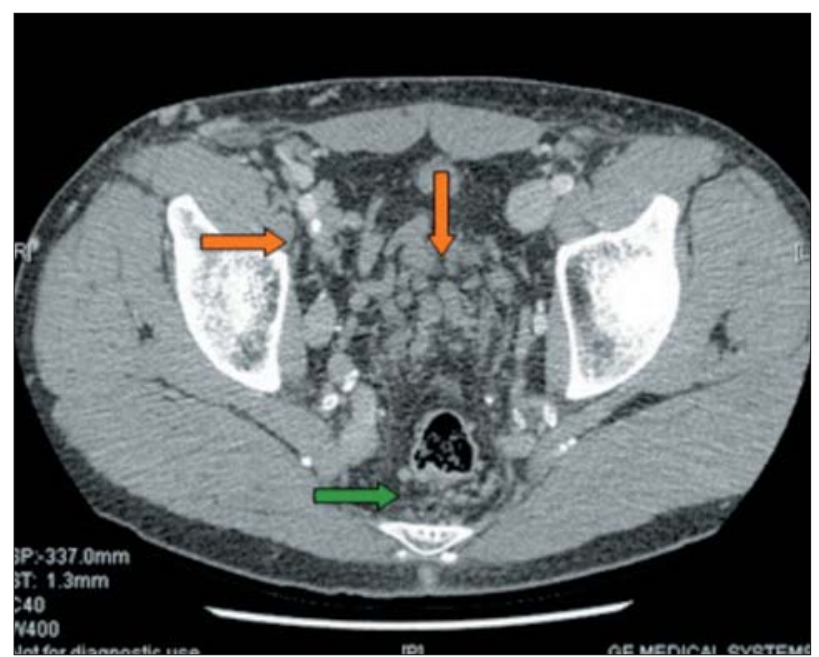

Figure 3. - Axial CT image shows extensive pelvic collateral venous pathways (orange arrows). Green arrow indicates enlarged perirectal venous plexi.

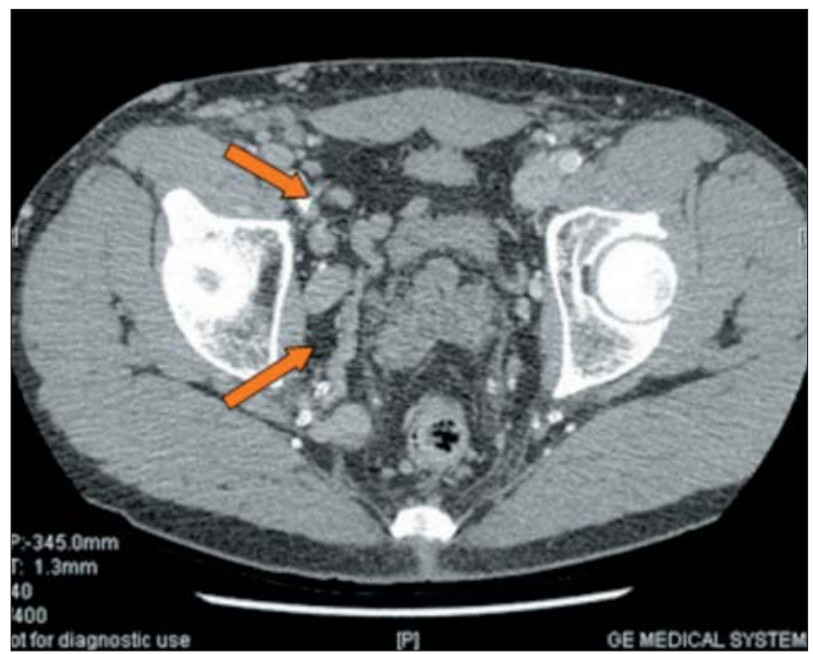

Figure 4. - More caudal axial CT scan showing collateral venous varices along the course of chronically thrombosed right external iliac vein (arrows). 
syndrome, lower back pain, varicocele, chronic venous diseases of the lower limbs, hepatic engorgement, cardiac failure and pulmonary embolism have also been described [4].

Idiopathic IVC thrombosis is very rare. Chikaraishi et al. described a case of apparent idiopathic IVC thrombosis in a 57-year old woman presented with chest pain secondary to pleurisy and a background history of pyelonephritis but no other prothrombotic condition [5].

An endemic variant of IVC thrombosis in Nepalese patients has been also described [6]. This condition is characterized by obstruction or stenosis of the IVC hepatic segment with associated hepatic venous outflow obstruction. Reliable evidences suggest an infective etiology which results in thrombophlebitis, thrombus formation and subsequent fibrotic stenosis [7]. Organisms thought to be involved are Staphylococcus Aureus and gram-negative enteric organisms, whose bacteremia leads to a transient protein-S deficiency [7].

Congenital malformations of the IVC are unusual with a prevalence of $0.3 \%$ to $0.6 \%$ in the general population [8]. IVC is created by the fusion of three sets of paired veins (posterior cardinal, subcardinal and supracardinal veins) during week six to eight of embrionic development [9]. The failure of these paired veins to fuse into a unilateral rightsided venous system is the main mechanism which leads to an anomalous IVC [9]. Interruptions or absences of the IVC are often limited to the intra-hepatic segment. Their prevalence increases to $2 \%$ in patients with other congenital cardiovascular abnormalities such as transposition of the great vessels, dextrocardia, and pulmonary artery stenosis [8]. Co-existent visceral anomalies include asplenia, polysplenia, situs inversus and hypoplasia of the kidney [10].

Inherited thrombophilic disorders strongly increase the risk of IVC thrombosis. These include: factor V Leiden, mutation of factor II (prothrombin) gene, homozygous C667T mutation in the methylentetrahydrofolate reductase gene, antithrombin deficiency, protein $\mathrm{C}$ and $\mathrm{S}$ deficiency, dysfibrinogenemia, homozygous homocystinuria and increased levels of factors VIII, IX, XI and fibrinogen [1].

The interaction between acquired and genetic causes makes it difficult to decide which patients should be tested for inherited thrombophilia, what tests to perform and when.

The gold standard for the diagnosis of deep vein thrombosis remains contrast venography. However, it is an invasive procedure associated with a $2-10 \%$ rate of postprocedural DVT [2]. Ultrasound scanning is now the first-line investigative modality, although it is operator dependant and can be limited by body habitus and occasionally fails to identify any IVC abnormality [11]. CT is a non-invasive method which can accurately diagnose and assess the extent of thrombus as well as delineate any associated IVC anomaly [2]. MRI is now replacing CT as the optimal diagnostic tool, giving more accurate delineation of thrombus as well as any IVC anomaly and avoiding ionizing radiations.

Chronic thrombosis of the IVC is usually treated with anticoagulation. There are no studies in sci- entific literature describing the ideal duration of anticoagulation therapy in this condition; however, clinical evidence shows a trend toward treatment for a minimum of one year. The coexistence of inherited coagulative disorders makes often necessary to continue oral anticoagulation indefinitely. Furthermore, a caval anomaly is a permanent risk factor for venous stasis and thrombosis and anticoagulation therapy should be lifelong [12].

Other options for treatment of IVC thrombosis without anatomical variance include mechanical thrombectomy, angioplasty and stent placement, systemic thrombolysis, transcatheter regional thrombolysis, pulse-spray pharmacomechanical thrombolysis [2, 13]. Surgical reconstruction of the IVC is sometimes feasible for the most severe cases and is associated with considerable morbidity and mortality risk [14]. Interventional techniques are limited by anatomical factors such as the extent of thrombus, the involvement of the IVC branches (particularly renal and hepatic veins), the presence of extensive collateral compensatory venous circulation and the presence of congenital caval aberrancy and abnormalities.

This case we described represents an example of how inherited and acquired conditions interact in causing IVC thrombosis. Patient was carrier of a heterozygous mutation of the MTHFR gene that, per se, unlikely causes the formation of an IVC thrombus; furthermore he was subject, as resulted from his clinical history, to a trauma due to a prolonged squatted position as a consequence of his work. We hypothesized, in fact, that this event provoked a silent and transient retroperitoneal hematoma to the iliopsoas muscle which led, via mass effect, to compression of the IVC, hence the formation of an intraluminal thrombus.

\section{Conclusion}

The diagnosis of this condition requests a high index of suspicion in young patients with lower limbs and back pain, dilatation of superficial abdominal veins, varicocele and a persistent increase of inflammatory markers. Although ultrasound scanning is the first line diagnostic technique, CT and/or MRI are mandatory for the exact definition of IVC thrombus and presence of IVC congenital abnormalities. Although percutaneous and surgical therapeutic modalities exist, long-term or often lifelong oral anticoagulation is required. Warfarin is cumbersome to use, because of its multiple interactions with food and drugs, and it requires frequent laboratory monitoring. Therefore, it is often not used and rates of discontinuation are high [15]. Many patients receiving warfarin still present inadequate anticoagulation [16]. The use of new safe, effective and convenient to use anticoagulant drugs is a hope for patients with IVC thrombosis and any type of DVT. We think that efforts must be made to promote clinical trials comparing classical anticoagulant agents (vitamin K antagonists such as warfarin) with new agents, such as as dabigatran etexilate, a direct thrombin inhibitors, which has recently demonstrated to be effective and convenient to use in patients with atrial fibrillation [17]. 


\section{Riassunto}

L'incidenza di trombosi venosa profonda (TVP) nella popolazione generale è approssimativamente pari allo $0.1 \%$ e risulta ancora più bassa al di sotto dei 40 anni di età. La trombosi della vena cava inferiore (VCI) è una condizione clinica eccezionalmente rara, con fattori eziologici analoghi a quella della trombosi del sistema venoso profondo degli arti inferiori. In questo lavoro viene presentato un caso di ostruzione cronica post-traumatica della VCI in un giovane adulto, verosimilmente conseguente ad un prolungato accovacciamento. Il paziente si è presentato alla nostra attenzione, quindici anni dopo l'insorgenza del quadro clinico, per una grave sindrome posttrombotica, coinvolgente in particolar modo l'arto inferiore destro. Lo screening della trombofilia ereditaria ha documentato una mutazione eterozigote del gene codificante per la metilentetraidrofolatoreduttasi (MTHFR). La TAC ha confermato l'occlusione trombotica della VCI infraepatica, di entrambe le vene iliache comuni, delle iliache interna ed esterna destra, con multipli circoli collaterali. A causa della estensione della trombosi, della presenza di fattori protrombotici ereditari e della relativamente giovane età del paziente, abbiamo optato per la terapia anticoagulante orale a tempo indefinito.

Parole chiave: trombosi venosa profonda, trombosi vena cava inferiore, trombofilia congenita, terapia anticoagulante orale.

\section{ACRONYMS}

IVC: inferior vena cava

DVT: deep venous thrombosis

CT: computed tomography

MRI: Magnetic Resonance Imaging

MTHFR: methylenetetrahydrofolate reductase

\section{References}

1. Seligsohn U, Lubetsky A. Genetic susceptibility to venous thrombosis. N Engl J Med 2001; 344(16): 1222-1231.

2. Giordano P, Weber K, Davis M, Carter E. Acute thrombosis of the inferior vena cava. Am J Emerg Med 2006; 24(5): 640-642.

3. Silverstein MD, Heit JA, Mohr DN, Petterson TM, O'Fallon WM, Melton LJ, 3rd. Trends in the incidence of deep vein thrombosis and pulmonary embolism: a 25-year populationbased study. Arch Intern Med 1998; 158(6): 585-593.

4. Jackson BT, Thomas ML. Post-thrombotic inferior vena caval obstruction. A review of 24 patients. $\mathrm{Br}$ Med $J$ 1970; 1(5687): 18-22.

5. Chikaraishi T, Kobayashi S, Harada H, Komaki T, Koyanagi $\mathrm{T}$. Idiopathic and spontaneously regressing thrombus in right renal vein and inferior vena cava. Int J Urol 1997; 4(1): 83-85.

6. Shrestha SM. Hepatic venous outflow obstruction in Nepal. Trop Gastroenterol 1996; 17(3): 165-171.

7. Shrestha S. Bacterial peritonitis in hepatic inferior vena cava disease: a hypothesis to explain the cause of infection in high protein ascites. Hepatol Res 2002; 24(1): 42.

8. Chuang VP, Mena CE, Hoskins PA. Congenital anomalies of the left renal vein: angiographic consideration. $\mathrm{Br}$ J Radiol 1974; 47(556): 214-218.

9. Salgado Ordonez F, Gavilan Carrasco JC, Bermudez Recio FJ, Aguilar Cuevas R, Fuentes Lopez T, Gonzalez Santos P. Absence of the inferior vena cava causing repeated deep venous thrombosis in an adult - a case report. Angiology 1998; 49(11): 951-956.

10. Tsuji Y, Inoue T, Murakami H, Hino Y, Matsuda H, Okita Y. Deep vein thrombosis caused by congenital interruption of the inferior vena cava - a case report. Angiology 2001; 52(10): 721-725.

11. Park JH, Lee JB, Han MC, et al. Sonographic evaluation of inferior vena caval obstruction: correlative study with vena cavography. AJR Am J Roentgenol 1985; 145(4): 757-762.

12. Dean SM, Tytle TL. Acute right lower extremity iliofemoral deep venous thrombosis secondary to an anomalous inferior vena cava: a report of two cases. Vasc Med 2006; 11(3): 165-169.

13. Yamada N, Ishikura K, Ota S, et al. Pulse-spray pharmacomechanical thrombolysis for proximal deep vein thrombosis. Eur J Vasc Endovasc Surg 2006; 31(2): 204-211.

14. Robbins MR, Assi Z, Comerota AJ. Endovascular stenting to treat chronic long-segment inferior vena cava occlusion. J Vasc Surg 2005; 41(1): 136-140.

15. Hylek EM, Evans-Molina C, Shea C, Henault LE, Regan $\mathrm{S}$. Major hemorrhage and tolerability of warfarin in the first year of therapy among elderly patients with atrial fibrillation. Circulation 2007; 115(21): 2689-2696.

16. Connolly SJ, Pogue J, Eikelboom J, et al. Benefit of oral anticoagulant over antiplatelet therapy in atrial fibrillation depends on the quality of international normalized ratio control achieved by centers and countries as measured by time in therapeutic range. Circulation 2008; 118(20): 2029-2037.

17. Connolly SJ, Ezekowitz MD, Yusuf S, et al. Dabigatran versus Warfarin in Patients with Atrial Fibrillation. $N$ Engl J Med 2009. 